\title{
Biosorption of Methylene Blue from Aqueous Solution by Coconut (Cocos nucifera) Shell-derived Activated Carbon-chitosan Composite
}

\author{
PRECIOUS CAREE V. REGUNTON ${ }^{1}$, DERICK ERL P. SUMALAPAO2,3, * \\ and NELSON R. VILLARANTE ${ }^{1}$
}
${ }^{1}$ Department of Physical Sciences and Mathematics, College of Arts and Sciences, University of the Philippines Manila, Manila, Philippines.
${ }^{2}$ Department of Biology, College of Science, De La Salle University, Manila, Philippines.
${ }^{3}$ Department of Medical Microbiology, College of Public Health, University of the
Philippines Manila, Manila, Philippines.
${ }^{*}$ Corresponding author E-mail: derick.sumalapao@dlsu.edu.ph

http://dx.doi.org/10.13005/ojc/340113

(Received: August 23, 2017; Accepted: December 30, 2017)

\begin{abstract}
Charcoal produced from coconut shells through the retort method was consequently activated using $\mathrm{CaCl}_{2}$. The activated carbon-chitosan composite was prepared by coating the activated carbon with chitosan. Batch experiments with methylene blue as adsorbate were conducted under varying $\mathrm{pH}$, contact time, initial dye concentration, adsorbent dosage, and temperature. The effects of these factors were investigated using batch adsorption studies with optimal conditions identified at $\mathrm{pH} \mathrm{5,30} \mathrm{min.} \mathrm{contact} \mathrm{time,} 10 \mathrm{mg} \mathrm{L}^{-1}$ initial dye concentration, $9 \mathrm{~g} \mathrm{~L}^{-1}$ adsorbent dosage, and $25^{\circ} \mathrm{C}$ adsorption temperature. Results of adsorption experiments showed that the composite had better removal efficiency compared to activated carbon.
\end{abstract}

Keywords: Methylene blue, Biosorption, Cocos nucifera, Carbon-chitosan composite, Retort method, Biocharcoal, Coconut shell.

\section{INTRODUCTION}

Anthropogenic activities and rapid industrialization have contributed to the worsening of environmental conditions by generating huge quantities of pollutants that are most often than not discharged into the nearest water sources. Among these contaminants which include toxic heavy metals, metalloids, radionuclides and organic compounds, dyes are of serious concern because

This is an $\mathbf{C}$ Open Access article licensed under a Creative Commons Attribution-NonCommercial-ShareAlike 4.0 International License (https://creativecommons.org/licenses/by-nc-sa/4.0/ ), which permits unrestricted NonCommercial use, distribution and reproduction in any medium, provided the original work is properly cited. 
of their hazardous compounds content, suspended solids, high biological and chemical oxygen demands, and high visibility even at very low concentrations. The complex aromatic structures of dyes account for their non-biodegradability and recalcitrant nature, as exhibited by their stability against sunlight, temperature, oxidizing agents, and microbial attack ${ }^{1}$. Dye pollution poses a threat to humans' health and ecological equilibrium due to its mutagenic, carcinogenic, and teratogenic effects upon inhalation or dermal contact, and its inhibition of sunlight penetration that may consequently lead to the reduction of photosynthetic activities of aquatic organisms².

Among the various types of chemical and physical methods developed for the treatment of effluents, adsorption processes utilizing activated carbon are preferred due to its ease of application with good efficiency. However, commercial activated carbon is very expensive and non-renewable, which limits its practical utility especially for a large-scale setting. To address these drawbacks, production of activated carbon from cheap and renewable precursors, which are mainly agricultural by-products and wastes like coconut husks ${ }^{3}$ and coconut shells ${ }^{4}$, have been investigated. Another solution is by coating the activated carbon with a material that is not only less expensive but would also enhance its adsorption capacity ${ }^{5}$. Chitosan, with its high content of amino and hydroxyl functional groups and which is produced by alkaline $\mathrm{N}$ deacetylation of chitin, exhibits high adsorption potential for a wide range of molecules such as phenolic compounds, dyes, and metal ions ${ }^{6}$. The use of biomass and biomaterials for separation of dissolved or suspended target substances from solutions is generally referred to as biosorption, a physico-chemical and metabolically-independent process that has been gaining immense interest as an alternative to conventional techniques. Hence, this study prepared coconut shell-derived activated carbon-chitosan composite as a potential biosorbent material for the removal of methylene blue in an aqueous solution by adsorption process. Moreover, the influence of $\mathrm{pH}$, contact time, dye concentration, adsorbent dosage, and temperature on the adsorption process were also determined. This study also compared the removal efficiency of coconut shell-derived carbon-chitosan composite with the activated biocharcoal in the removal of methylene blue. Conversion of the widely-available agricultural wastes such as coconut shells to biocharcoal was done using a simple and low-cost method that can be adapted globally.

\section{MATERIALS AND METHODS}

\section{Materials and Reagents}

Activated carbon was prepared from coconut shells obtained from a local market in Laguna, Philippines. Calcium chloride was purchased from Qualikems Fine Chem. Pvt. Ltd., India. Commercial chitosan $(75 \%$ degree of deacetylation) was purchased from Sigma-Aldrich, Singapore. Pure methylene blue $\left(\mathrm{C}_{16} \mathrm{H}_{18} \mathrm{CIN}_{3} \mathrm{~S}\right)$ was obtained from HiMedia, India and was used to prepare a stock solution of concentration $50 \mathrm{mg} \mathrm{L}^{-1}$. Serial dilutions were performed to prepare lower concentrations of the dye. The $\lambda_{\max }$ of methylene blue and the absorbance of the dye solutions were determined using a Jenway 7315 spectrophotometer. Other reagents including $\mathrm{HCl}, 99 \%$ sodium hydroxide were obtained from $\mathrm{RCl}$ Labscan and oxalic acid $\left(\mathrm{C}_{2} \mathrm{H}_{2} \mathrm{O}_{4} \cdot 2 \mathrm{H}_{2} \mathrm{O}\right)$ from HiMedia Laboratories Ltd., Mumbai. All solutions were prepared with deionized water, which was obtained from a local supplier. The $\mathrm{pH}$ of the solutions was adjusted with $0.1 \mathrm{M} \mathrm{HCl}$ and $0.1 \mathrm{M} \mathrm{NaOH}$ and was measured using a Sartorius Docu- $\mathrm{pH}^{+}$meter.

\section{Preparation of Coconut Shell Biocharcoal}

Dry coconut shells were washed several times with tap water to remove dust and other soluble impurities. These were then crushed into small pieces, washed with deionized water, and ovendried. Charcoal production was performed using the retort method ${ }^{7}$. An empty tin can was filled with the dried coconut shells and sealed with its lid, with few small holes drilled on the bottom part. The carbonization process was performed for 4- $6 \mathrm{~h}$ by placing the can, surrounded with wood and paper materials, inside a bigger tin can with holes as vents and subsequently ignited from above. The thoroughly carbonized material was segregated and used in the subsequent experiments.

\section{Activation Process}

The charcoals were pulverized, sieved to 60 -mesh, and soaked in $25 \%$ solution of $\mathrm{CaCl}_{2}$ for 
$24 \mathrm{~h}$, and then rinsed thoroughly with deionized water and dried in an oven at $100{ }^{\circ} \mathrm{C}$ until constant weight ${ }^{7,8}$.

\section{Preparation of Activated Carbon-Chitosan Composite}

The composite was prepared by coating the activated carbon with chitosan ${ }^{9,10}$. Twenty-five grams $(25 \mathrm{~g})$ chitosan was added to $1 \mathrm{~L}$ of $0.4 \mathrm{M}$ oxalic acid solution under continuous stirring at $45-50{ }^{\circ} \mathrm{C}$ to facilitate formation of gel ${ }^{10}$. About $50 \mathrm{~g}$ of the activated carbon was slowly added to chitosan gel and stirred for $16 \mathrm{~h}$, keeping the temperature at $45-50{ }^{\circ} \mathrm{C}$. The composite was then prepared by dropwise addition of the activated carbon-chitosan gel mixture ${ }^{11}$ into a $1 \mathrm{M} \mathrm{NaOH}$ bath, and washed several times with deionized water to a neutral $\mathrm{pH}^{9}$. It was dried in an oven at $100{ }^{\circ} \mathrm{C}$ until constant weight. A grinder was then used to reduce the size of the activated carbonchitosan composite and particle size of 40-mesh $(0.400 \mu \mathrm{m})$ size was used in the adsorption study.

\section{Batch Adsorption Studies}

The effects of various reaction parameters such as $\mathrm{pH}$, contact time, dye concentration, adsorbent dosage, and temperature on the adsorption process were evaluated. The flasks were kept closed to avoid fluctuation of $\mathrm{pH}$. Adsorbent was separated from the solution via centrifugation. The blank for spectrophotometric determination consisted of deionized water. The experiments were performed in triplicates and the mean values were used for succeeding calculations. The same conditions were also applied to an adsorption system utilizing activated carbon to compare the efficiency of the two adsorbents. The dye uptake was computed using Equation 1, whereas the dye removal efficiency, indicated by Removal (\%), was calculated using Equation 2.

$\mathrm{qe}_{\mathrm{e}}=\frac{\left(\mathrm{C}_{\mathrm{o}}-\mathrm{C}_{\mathrm{e}}\right) \mathrm{V}}{\mathrm{M}}$

Removal $(\%)=\frac{\left(C_{0}-C_{e}\right)}{C_{0}} \times 100$

where:

$\mathrm{q}_{\mathrm{e}}=$ biosorption capacity at equilibrium $\left(\mathrm{mg} \mathrm{g}^{-1}\right)$

$\mathrm{C}_{0}=$ initial dye concentration $\left(\mathrm{mg} \mathrm{L}^{-1}\right)$

$\mathrm{C}_{\mathrm{e}}=$ equilibrium dye concentration $\left(\mathrm{mg} \mathrm{L}^{-1}\right)$

$\mathrm{V}=$ volume of the solution $(\mathrm{L})$

$\mathrm{M}=$ adsorbent dosage $(\mathrm{g})$

\section{Effect of pH}

One gram per liter $\left(1 \mathrm{~g} \mathrm{~L}^{-1}\right)$ adsorbent was added to $20 \mathrm{~mL}$ methylene blue dye solution of concentration $10 \mathrm{mg} \mathrm{L}^{-1}$ at different $\mathrm{pH}$ values $(4,5$, 6,7 , and 8 ) and temperature of $30^{\circ} \mathrm{C}$. The solution was agitated at $150 \mathrm{rpm}$ for 30 minutes.

\section{Effect of Contact Time}

One gram per liter $\left(1 \mathrm{~g} \mathrm{~L}^{-1}\right)$ of the adsorbent was added to $20 \mathrm{~mL}$ methylene blue dye solution of concentration $10 \mathrm{mg} \mathrm{L}^{-1}$ at optimum $\mathrm{pH}$ and temperature of $30{ }^{\circ} \mathrm{C}$. The solution was agitated at constant speed (150 rpm) for different time intervals $(15,30,45,60$, and 75 minutes).

\section{Effect of Initial Dye Concentration}

One gram per liter $\left(1 \mathrm{~g} \mathrm{~L}^{-1}\right)$ of the adsorbent was added to $20 \mathrm{~mL}$ methylene blue dye solution of different concentrations $\left(2,4,6,8\right.$, and $\left.10 \mathrm{mg} \mathrm{L}^{-1}\right)$ at optimum $\mathrm{pH}$ and temperature of $30^{\circ} \mathrm{C}$. The solution was agitated at $150 \mathrm{rpm}$ for optimum contact time.

\section{Effect of Adsorbent Dosage}

Various amounts of the adsorbent $(1,2,3$, 4, 5, 6, 7, 8, and $9 \mathrm{~g} \mathrm{~L}^{-1}$ ) were added to $20 \mathrm{~mL}$ methylene blue dye solution at optimum concentration, $\mathrm{pH}$, and temperature of $30^{\circ} \mathrm{C}$. The solution was agitated at $150 \mathrm{rpm}$ for optimum contact time.

\section{Effect of Temperature}

One gram per liter $\left(1 \mathrm{~g} \mathrm{~L}^{-1}\right)$ of the adsorbent was added to $20 \mathrm{~mL}$ methylene blue dye solution at optimum concentration, $\mathrm{pH}$, and different temperature $\left(25,40,50\right.$, and $\left.60^{\circ} \mathrm{C}\right)$. The solution was agitated at $150 \mathrm{rpm}$ for optimum time.

\section{RESULTS AND DISCUSSION}

\section{Batch Adsorption Studies}

Solid-liquid adsorption system is assessed usually employing either the batch adsorption tests or the dynamic continuous-flow adsorption tests ${ }^{12}$, the former of which was used in this study. In batch adsorption studies, which are relatively cheap and simple procedures, the different biosorption parameters can be easily adjusted, monitored, and optimized. Prior to the experiments, a wavelength scan of an aqueous solution of methylene blue was done to determine its $\lambda_{\max }$. The maximum absorbance of 1.847 
occurred at a wavelength of $665 \mathrm{~nm}$ (Fig. 1), and this wavelength was used in further absorbance measurements.

\section{Effect of $\mathrm{pH}$}

The $\mathrm{pH}$ of the dye solution plays a key role in the adsorption process by influencing the surface charge of the biosorbent, degree of ionization of the compounds present ${ }^{13}$, dissociation of functional groups, and the solution dye chemistry. Hydrogen and hydroxyl ions are adsorbed quite strongly and therefore, the adsorption of other ions is affected by the $\mathrm{pH}$ of the solution ${ }^{14,15}$. Chitosan, which is a weak base and is relatively insoluble in water and in some organic solvents, is highly soluble in dilute aqueous acidic solutions $(\mathrm{pH}<6.5)^{12}$. Chitosan has $\mathrm{pK}_{a}$ values ranging from 6.5 to 6.7 depending on the degree of deacetylation, ionic strength, and charge neutralization of the amine groups ${ }^{16}$. Moreover, chitosan forms gels at lower $\mathrm{pH}$ and precipitates in alkaline solution or with polyanions ${ }^{12}$.

The effect of $\mathrm{pH}$ on the adsorption of methylene blue by activated carbon-chitosan composite was determined by varying the $\mathrm{pH}$ from 4 to 8 (Fig. 2). Highly acidic conditions were not included in the study because of the apparent disintegration of the composite. This indicates dissociation of the chitosan from the activated carbon since the former is soluble in acidic media. Highly alkaline conditions were also excluded because of the formation of hydrogen bonds between the amine groups of chitosan, which caused a decreased in the number and diameter of the pores, thus effectively decreasing the dye uptake $^{17}$. In this study, the maximum uptake was observed at pH 5 (Figure. 2).

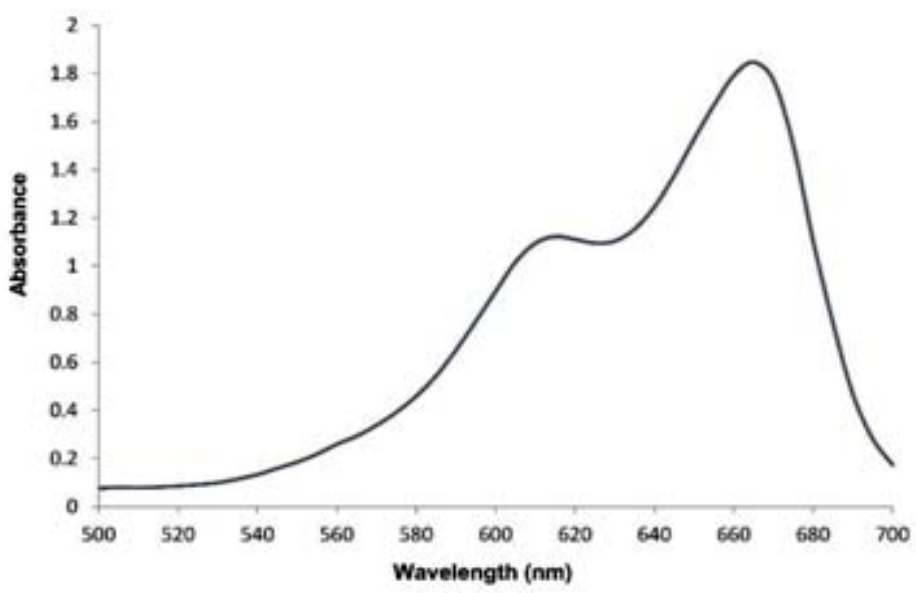

Fig.1. Wavelength scan of $10 \mathrm{mg} \mathrm{L}^{-1}$ methylene blue aqueous solution

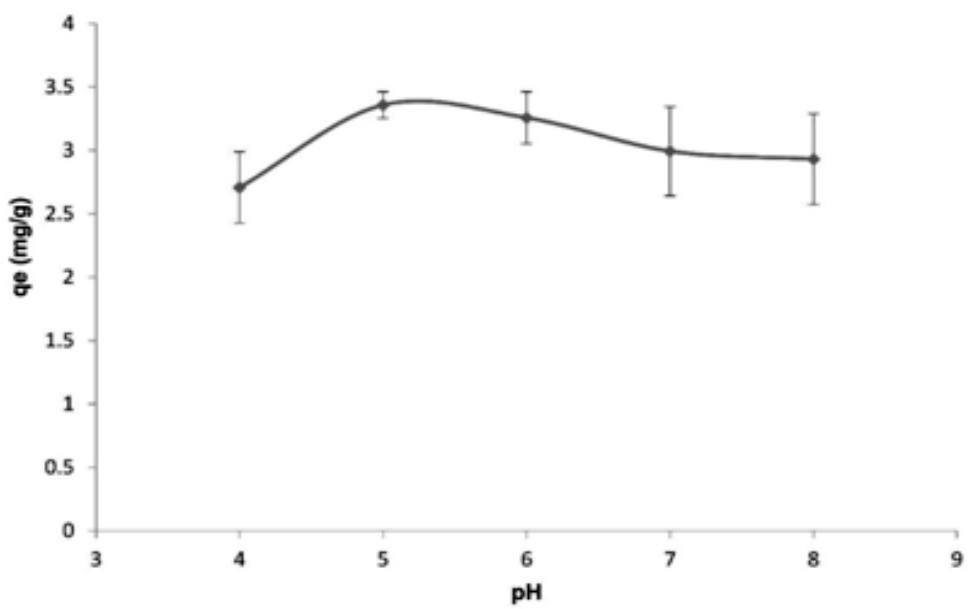

Fig. 2. Methylene blue uptake in an aqueous solution at varying $\mathrm{pH}$ values 


\section{Effect of Contact Time}

In adsorption process, contact time is one of the important parameters to monitor because it provides pertinent information on the adsorption capacity, desorption efficiency, and regeneration potential of the adsorbent ${ }^{12}$. Rapid increase in dye uptake was observed in the first $30 \mathrm{~min}$. and subsequently decreased thereafter (Fig. 3). These changes in the dye uptake may be due to, initially, the adsorbent sites were all available for binding of the adsorbate molecules ${ }^{5,18}$. During the process, the surface of the activated carbon-chitosan composite was saturated with methylene blue, thus preventing the binding of additional dye molecules. At 30 min., saturation of the sites was observed and hence, equilibrium was attained. However, analyses beyond this period showed decreasing dye uptake which can be attributed to the desorption of the dye adsorbate from the composite. This gives a good opportunity for the regeneration and recycling of the composite for another batch of adsorption. The dye uptake at $30 \mathrm{~min}$. contact time was $3.357 \mathrm{mg} \mathrm{g}^{-1}$ (Figure. 3).

\section{Effect of Initial Dye Concentration}

In an adsorption process, the initial dye concentration reflects the amount of dye molecules available for binding. Generally, at constant adsorbent dosage, dye uptake increases with increase in dye concentration due to mass transfer phenomenon. The dye removal efficiency, on the other hand, decreased with an increase in the initial dye concentration, which can be attributed to the saturation of the adsorption sites ${ }^{5,18}$. In this study, methylene blue-composite system obeyed these general trends (Figure. 4).

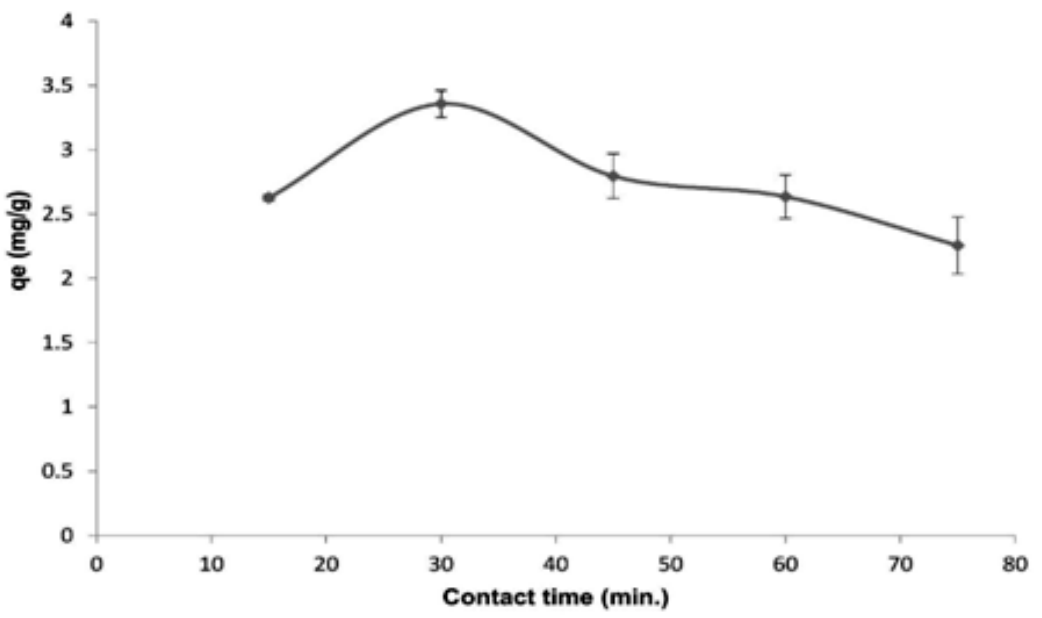

Fig. 3. Methylene blue uptake in an aqueous solution at varying contact time

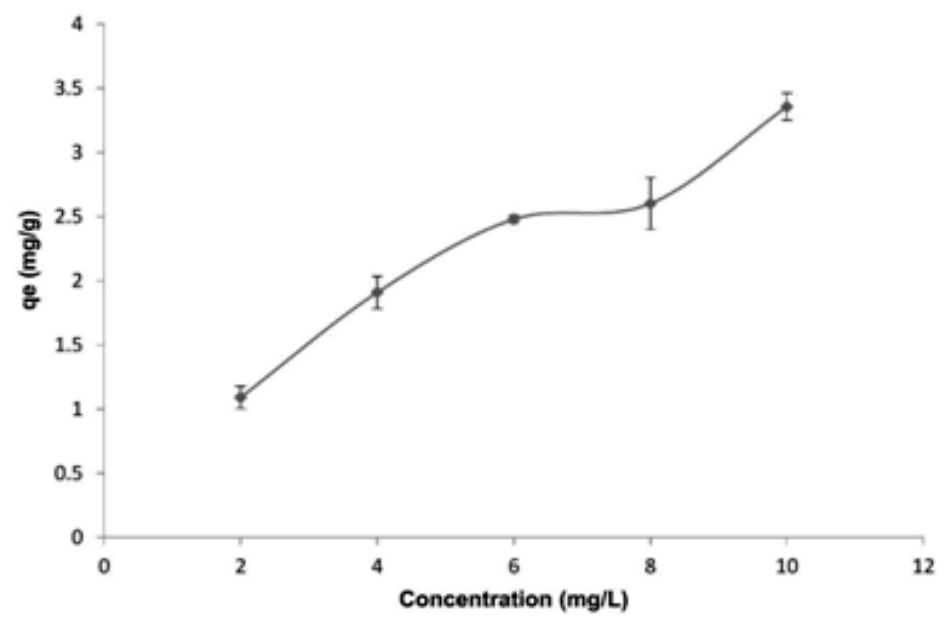

Fig. 4. Methylene blue uptake in an aqueous solution at varying initial dye concentrations 
Methylene blue molecules tend to diffuse from the solvent (water) towards the surface of the activated carbon-chitosan composite because of concentration gradient. The driving force of this factor increased with an increase in the initial dye concentration, and hence led to greater dye uptake (Fig. 4). The maximum dye uptake of $3.357 \mathrm{mg} \mathrm{g}^{-1}$ was observed at $10 \mathrm{mg} \mathrm{L}^{-1}$ of methylene blue solution corresponding to $33.57 \%$ removal efficiency. However, the residual concentration of dye molecules, that is the amount of methylene blue molecules not taken up by the adsorbent, increased with higher initial concentration. This explains the decrease in the dye removal efficiency whose maximum value of $54.54 \%$ corresponding to a dye uptake of $1.091 \mathrm{mg} \mathrm{g}^{-1}$ was observed at $2 \mathrm{mg} \mathrm{L}^{-1}$ methylene blue solution (Fig. 5). This point is made evident in Table. 1, where $C_{e}$ represents the concentration of methylene blue solution after adsorption.

\section{Effect of Adsorbent Dosage}

Adsorbent dosage is an important parameter since it determines the capacity of an adsorbent for a given amount of adsorbate at specified conditions. Increasing the adsorbent dosage generally increased the removal efficiency due to increased adsorbent surface and availability of more adsorption sites ${ }^{5,14,18}$. However, if the adsorption capacity was expressed as milligram adsorbed per gram of material, as in the case of dye uptake, a decrease was observed with increasing dosage due to the overlapping or aggregation of adsorption sites $^{12}$. In this study, these trends were followed by the methylene blue-composite adsorption system (Fig. 6). Comparison of the dye uptake and dye removal efficiency at varying adsorbent dosages is shown in Table. 2. The optimum adsorbent dosage was 9 $\mathrm{g} \mathrm{L}^{-1}$ with a dye uptake of $1.003 \mathrm{mg} \mathrm{g}^{-1}$ corresponding to $90.61 \%$ removal efficiency (Fig 7 ). Despite the low dye uptake per gram of the material, it must be noted that the presence of more amount of adsorbate resulted in a very high overall efficiency.

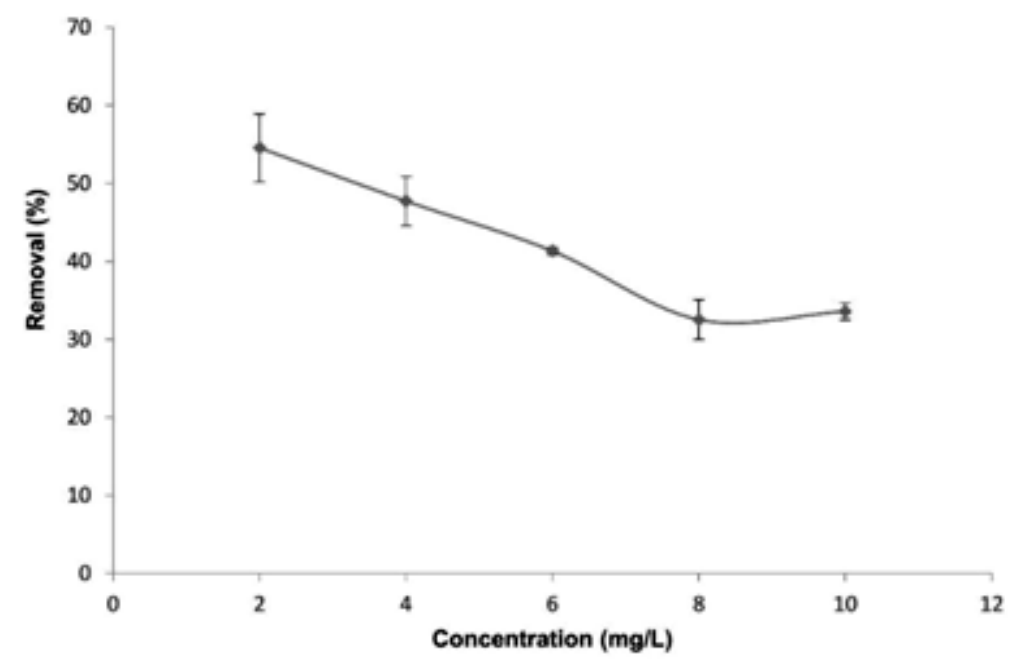

Fig. 5. Methylene blue removal efficiency at varying initial concentrations of dye adsorbate

Table. 1: Comparison of the dye uptake and dye removal efficiency of varying initial concentrations of methylene blue solutions

\begin{tabular}{lccc}
\hline $\begin{array}{l}\text { Initial } \\
\begin{array}{l}\text { Concentration } \\
\left(\mathrm{mg} \mathrm{L}^{-1}\right)\end{array}\end{array}$ & $\begin{array}{c}\mathrm{C}_{\mathrm{e}} \\
\left(\mathrm{mg} \mathrm{L}^{-1}\right)\end{array}$ & $\begin{array}{c}\text { Dye Uptake } \\
\left(\mathrm{mg} \mathrm{g}^{-1}\right)\end{array}$ & $\begin{array}{c}\text { Dye Removal } \\
\text { Efficiency(\%) }\end{array}$ \\
\hline 2 & 0.909 & 1.091 & 54.54 \\
4 & 2.091 & 1.909 & 47.72 \\
6 & 3.520 & 2.480 & 41.32 \\
8 & 5.398 & 2.602 & 32.53 \\
10 & 6.643 & 3.357 & 33.57 \\
\hline
\end{tabular}




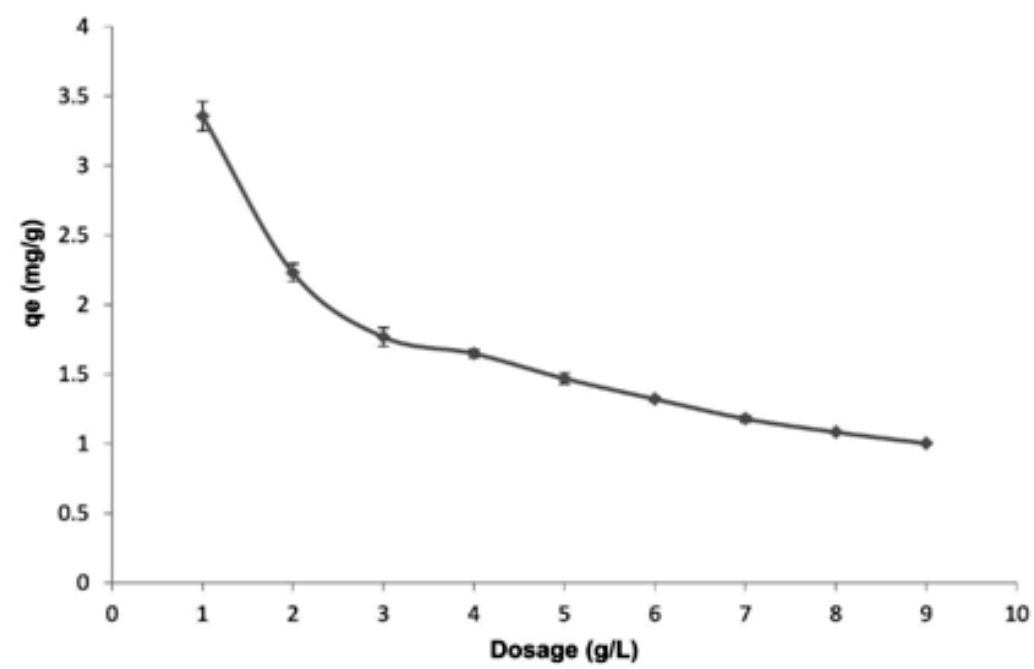

Fig. 6. Methylene blue uptake in an aqueous solution at varying adsorbent dosages

Table. 2: Comparison of the dye uptake and dye removal efficiency of the different adsorbent dosages

\begin{tabular}{cccc}
\hline Adsorbent Dosage $\left(\mathrm{g} \mathrm{L}^{-1}\right)$ & $\mathrm{C}_{\mathrm{e}}\left(\mathrm{mg} \mathrm{L}^{-1}\right)$ & Dye Uptake $\left(\mathrm{mg} \mathrm{g}^{-1}\right)$ & Dye Removal Efficiency $(\%)$ \\
\hline 1 & 6.643 & 3.357 & 33.57 \\
2 & 5.540 & 2.230 & 44.60 \\
3 & 4.695 & 1.768 & 53.05 \\
4 & 3.405 & 1.649 & 65.95 \\
5 & 2.651 & 1.470 & 73.49 \\
6 & 2.068 & 1.322 & 79.32 \\
7 & 1.740 & 1.180 & 82.60 \\
8 & 1.331 & 1.084 & 86.69 \\
9 & 0.939 & 1.003 & 90.61 \\
\hline
\end{tabular}

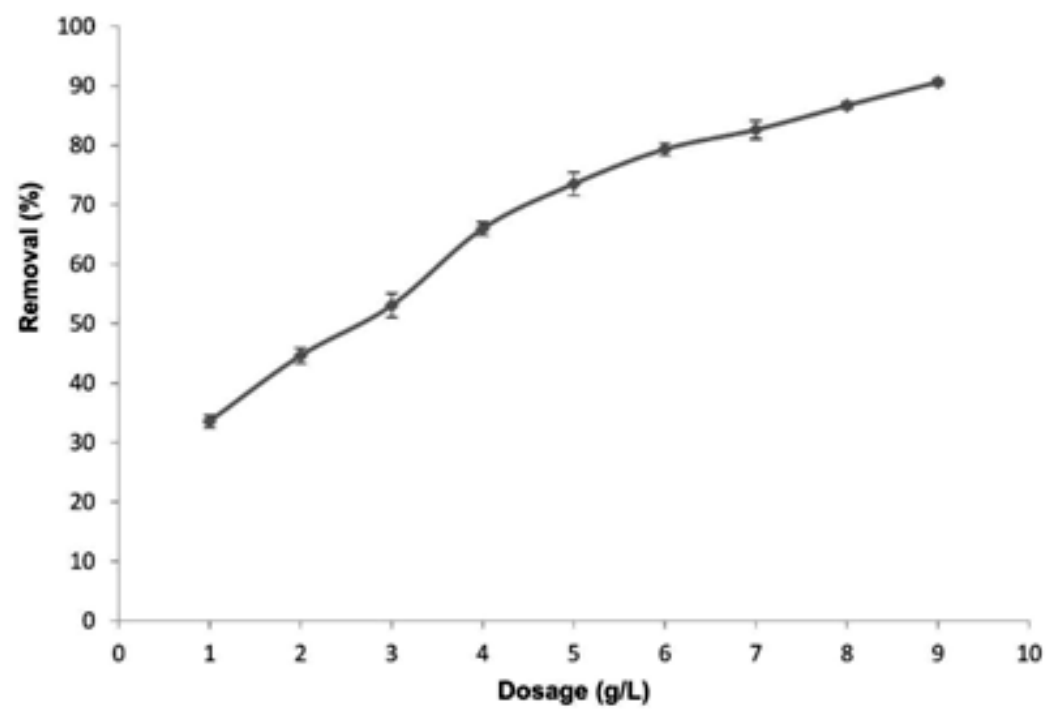

Fig.7. Methylene blue removal efficiency at varying adsorbent dosages 


\section{Effect of Temperature}

Temperature affects the adsorption capacity of the adsorbent. An increase in the adsorption capacity with increasing temperature indicates that the adsorption process is endothermic ${ }^{19}$, the mobility of the adsorbate molecules as well as the number of active sites for adsorption both increase at higher temperatures. On the other hand, a decrease in the adsorption capacity with increasing temperature indicates that the adsorption process is exothermic ${ }^{19}$. This may be attributed to higher temperatures decreasing the adsorptive forces between the adsorbate species and the active sites on the adsorbent surface resulting to a decreased adsorption capacity. The adsorption of methylene blue onto keratin nanofibrous membranes ${ }^{20}$ and the adsorption of acid red 88 dye onto bio-silica-chitosan composite $^{21,22}$ also showed this trend.

Increasing the temperature from 25 to $60{ }^{\circ} \mathrm{C}$ resulted in a decrease in dye uptake (Fig. 8). Hence, the adsorption of methylene blue to the surface of the activated carbon-chitosan composite is an exothermic process. Generally, adsorption of organic compounds including dyes is an exothermic process, thus increasing temperature weakens the binding interaction between the dye adsorbate and the active sites of the adsorbent ${ }^{12}$. In this study, the most favorable temperature was observed at $25^{\circ} \mathrm{C}$ with a dye uptake of $4.722 \mathrm{mg} \mathrm{g}^{-1}$ corresponding to $47.22 \%$ removal efficiency.

The favorable conditions determined in the batch studies were applied to compare the dye removal efficiency of the composite with that of activated carbon. The activated carbon and composite had dye uptakes of $0.966 \mathrm{mg} \mathrm{g}^{-1}$ and $1.009 \mathrm{mg} \mathrm{g}^{-1}$ corresponding to dye removal efficiencies of $86.94 \%$ and $90.77 \%$, respectively. This means that the composite was more efficient than the activated carbon. Since coating the activated carbon with chitosan up to five times had increased the thermal stability of the adsorbent and decreased the crystalline nature of the chitosan enhancing its adsorption efficiency on the removal of heavy metals ${ }^{23}$.

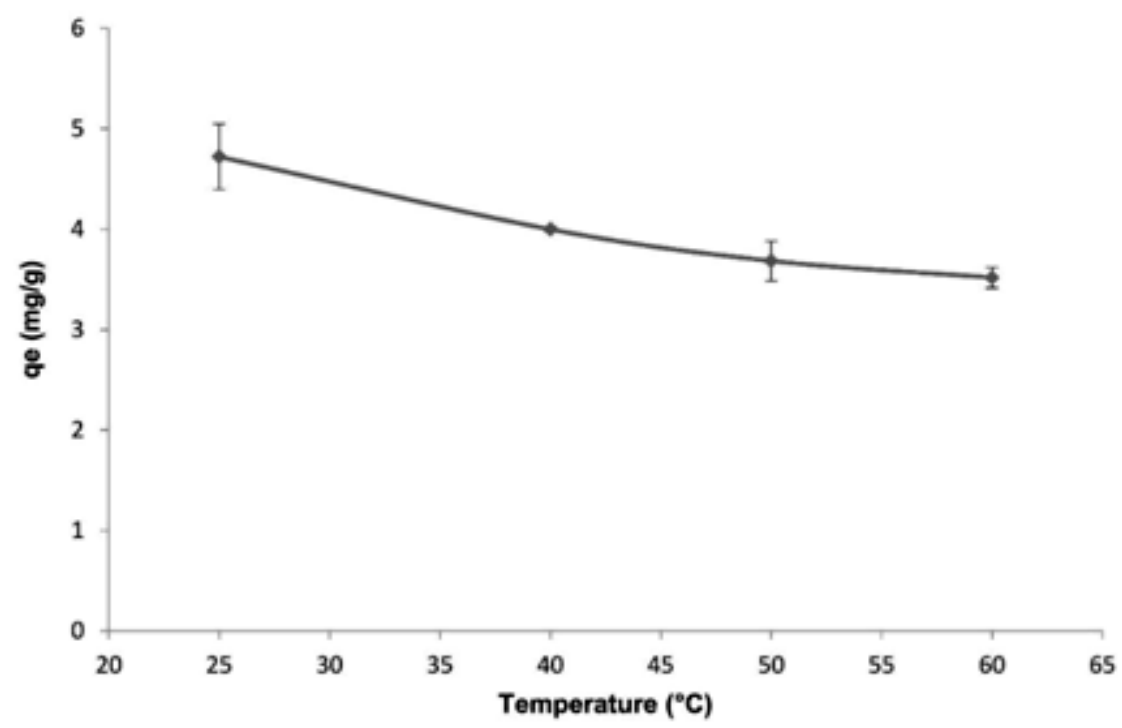

Fig. 8. Methylene blue uptake in an aqueous solution at varying temperature values

\section{CONCLUSION}

The activated carbon-chitosan composite was successfully prepared from coconut shells, $\mathrm{CaCl}_{2}$, and commercial chitosan. The effects of the different factors were investigated using batch studies and the most favorable conditions were determined at $\mathrm{pH}$ of $5,30 \mathrm{~min}$. contact time, $10 \mathrm{mg} \mathrm{L}^{-1}$ initial dye concentration, $9 \mathrm{~g} \mathrm{~L}^{-1}$ adsorbent dosage, and $25{ }^{\circ} \mathrm{C}$ adsorption temperature. Comparison with activated carbon showed that the composite had a better removal efficiency of $90.77 \%$. 


\section{REFERENCES}

1. Akar, S.; Gorgulu, A.; Akar, T.; Celik, S. Decolorization of reactive blue 48 contaminated solutions by Capsicum annuum seeds: Batch and continuous mode biosorption applications. Chemical Engineering Journal. 2011, 125-133.

2. Abdallah, R.; Taha, S. Adsorption of methylene blue from aqueous solution by nonviable Aspergillus fumigatus. Chemical Engineering Journal. 2012, 69-76.

3. Tan, I.; Ahmad, A.; Hameed, B. Enhancement of basic dye adsorption uptake from aqueous solutions using chemically modified oil palm shell activated carbon. Colloids and Surfaces. 2008, 88-96.

4. Ashish, S.; Aniruddha, M.; Prathmesh, S.; Dattatraya, P.; Prakash, R.; Mansing, A.; Sanjay, K. Removal of Bi (III) with adsorption technique using coconut shell activated carbon. Chinese Journal of Chemical Engineering. 2012, 768-775.

5. Villarante, N.R.; Bautista, A.P.R., Sumalapao, D.E.P. Batch adsorption study and kinetic profile of $\mathrm{Cr}(\mathrm{VI})$ using lumbang (Aleurites moluccana)-derived activated carbon-chitosan composite crosslinked with epichlorohydrin. Orient. J. Chem. 2017, 33(3), 1111-1119.

6. Zhang, J.; Liu, F. Adsorption of natural organic matter onto a composite adsorbent prepared with chitosan and powdered activated carbon. Desalination and Water Treatment. 2010.

7. Cobb, A.; Warms, M.; Maurer, E.; Chiesa, S. Low-tech coconut shell activated charcoal production. International Journal for Service Learning in Engineering. 2012, 93-104.

8. Renault, F. Cationized starch based material as a new ion exchanger adsorbent for the removal of C.I. Acid Blue 25 from aqueous solutions. Bioresource Technology. 2008.

9. Hydari, S.; Sharififard, H.; Nabavinia, M.; Parvizi, M. A comparative investigation on removal performances of commercial activated carbon, chitosan biosorbent and chitosan/ activated carbon composite for cadmium. Chemical Engineering Journal. 2012, 276-282.

10. Sharififard, H.; Soleimani, M.; Ashtiani, F.Z. Evaluation of activated carbon and biopolymer modified activated carbon performance for palladium and platinum removal. Journal of the Taiwan Institute of Chemical Engineers. 2012.

11. Sharififard, H.; Ashtiani, F.Z.; Soleimani, M. Adsorption of palladium and platinum from aqueous solutions by chitosan and activated carbon coated with chitosan: adsorption of palladium and platinum ions from aqueous solutions. Asia Pacific Journal of Chemical Engineering. 2012.

12. Crini, G.; Badot, P. Application of chitosan, a natural polysaccharide, for dye removal from aqueous solutions by adsorption processes using batch studies: A review of recent literature. Progress in Polymer Science. 2008, 399-447.

13. Greluk, M. Efficient removal of Acid Orange 7 dye from water using the strongly basic anion exchange resin Amberlite IRA958. Desalination. 2011.

14. Barka, N.; Abdennouri, M.; Makhfouk, M. Removal of methylene blue and Eriochrome Black $T$ from aqueous solutions by biosorption on Scolymus hispanicus L.: Kinetics, equilibrium and thermodynamics. Journal of the Taiwan Institute of Chemical Engineers. 2011, 320-326.

15. Doke, K. M.; Yusufi, M; Joseph, R.D.; Khan, E.M. Comparative adsorption of crystal violet and congo red onto $\mathrm{ZnCl}_{2}$ activated carbon. Journal of Dispersion Science and Technology. 2016.

16. Guibal, E. Heterogeneous catalysis on chitosan based materials: a review. Progress 
in Polymer Science. 2005.

17. Ngah, W.; Teong, L.; Hanafiah, M. Adsorption of dyes and heavy metal ions by chitosan composites: A review. Carbohydrate Polymers. 2011, 1446-1456.

18. Sumalapao, D.E.P.; Distor, J.R.; Ditan, I.D.; Domingo, N.T.S.; Dy, L.F.; Villarante, N.R. Biosorption kinetic models on the removal of congo red onto unripe calamansi (Citrus microcarpa) peels. Orient. J. Chem. 2016, 32(6), 2889-2900.

19. Yagub, M.; Sen, T.; Afroze, S.; Ang, H. Dye and its removal from aqueous solution by adsorption: A review. Advances in Colloid and Interface Science. 2014, 1-13.

20. Aluigi, A.; Rombaldoni, F.; Tonetti, C.; Jannoke, L. Study of methylene blue adsorption on keratin nanofibrous membranes. Journal of Hazardous Materials.
2014, 156-165.

21. Soltani, R.; Khatee, A.; Safari, M.; Joo, S. Preparation of bio-silica/chitosan nanocomposite for adsorption of textile dye in aqueous solutions. International Biodeterioration \& Biodegradation. 2013, 383-391.

22. Noorimotlagh, Z.; Darvishi Cheshmeh Soltani, R.; Khataee, A.R.; Shahriyar, S.; Nourmoradi, H. Adsorption of a textile dye in aqueous phase using mesoporous activated carbon prepared from Iranian milk vetch. Journal of the Taiwan Institute of Chemical Engineers. 2014.

23. Soundarrajan, M.; Gomathi, T.; Sudha, P. Understanding the adsorption efficiency of chitosan coated carbon on heavy metal removal. International Journal of Scientific and Research Publications. 2013, 1-10. 